\section{Tocilizumab in recent polymyalgia rheumatica: how can we manage the interleukin- 6 blockage?}

Thanks to Dr Moiseev et $a l^{1}$ for their very interesting opinions on the treatment of polymyalgia rheumatica (PMR) with tocilizumab (TCZ). In the TENOR study, ${ }^{2}$ for the first time, treatment other than glucocorticoid (GC) was able to control PMR. All patients received TCZ alone during 24 weeks. All parameters were improved: clinical symptoms, biological inflammation, patient's evaluation on disease activity, quality of life and imaging procedure. $^{3}$ This highlighted the role of interleukin-6 (IL-6) in the pathogenesis of the PMR and probably in giant cell arteritis. IL-6 was first described for its role in adaptive immunity but it also plays a fundamental role in innate immunity and regulates the acute-phase response raising the inflammatory aetiology of PMR.

In 2016, one of the new questions is the therapeutic strategy in PMR. Moiseev et al suggested TCZ agent as first-line therapy for PMR and asked about the side effects and cost-effectiveness of such therapy. Recent recommendation on PMR treatment ${ }^{4} 5$ did not suggest IL-6 inhibition but pointed out the side effect of GCs and recommend lower dosage with rapid decrease to obtain $10 \mathrm{mg} /$ day at week 8 and to add methotrexate if predictor of corticoresistence are present. All the recent data on TCZ suggest some modifications. ${ }^{6}$

In recent PMR, IL-6 inhibition should be considered in different cases: (1) for patients with associated comorbidities related to GC side effect (severe osteoporosis, diabetes), TCZ alone or in association with GC at lower doses following the TENOR protocol (ie, three infusions of TCZ and then a low dose of GC $(0.15 \mathrm{mg} / \mathrm{kg} /$ day according to the PMR-activity score (AS))); (2) for patients with recent side effects (fracture), TCZ alone; (3) for patients with corticodependence (inability to decrease GC) at week 8 and for GC dosage of more than $5 \mathrm{mg} /$ day.

In long-lasting PMR, studies are needed to confirm that IL-6 inhibition has also a dramatic effect and to better define the level of response and the side effects in elderly patients with longer GC impregnation. However, in such patients, TCZ seems to be the major option in association with GC and a protocol of rapid decrease of GC dosage.

Side effects related to the inhibition of IL- 6 should be closely monitored. They occur shortly after TCZ infusion and commonly include neutropenia, liver transaminases, serum lipid levels and alterations in cholesterol composition. Relationship with the dosage of TCZ is unknown but suggested. Moiseev et al suggested lower dosage of TCZ $(4 \mathrm{mg} / \mathrm{kg})$. In the TENOR study, where side effects were closely monitored, 59 infusions were administered, 52 at $8 \mathrm{mg} / \mathrm{kg}$ and 7 at $4 \mathrm{mg} / \mathrm{kg}$, meaning 'only'11\% had a lower dosage. So, our data suggest close monitoring and $8 \mathrm{mg} / \mathrm{kg}$ as the reference. These data need to be confirmed by future randomised trials and should also been considered with regards to the type of IL- 6 inhibitors. Targeting the IL-6 or the cognate IL-6 receptor or selectively blocking IL-6 trans-signalling could have different effects and side effects. ${ }^{7}$

Valérie Devauchelle, ${ }^{1}$ Alain Saraux ${ }^{2}$

${ }^{1}$ Brest University and La Cavale Blanche Hospital-Rheumatology, Brest, France ${ }^{2} \mathrm{CHU}$ Brest-Rheumatology, Bd Tanguy Prigent, Brest, France

Correspondence to Professor Valérie Devauchelle, Brest University and La Cavale Blanche Hospital—Rheumatology, BD Tanguy Prigent, Brest 29609, France; valerie. devauchelle-pensec@chu-brest.fr

Funding Roche-Chugai.

Competing interests None declared.

Patient consent Obtained.

Ethics approval CPP Ouest VI.

Provenance and peer review Commissioned; internally peer reviewed.

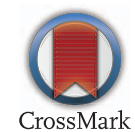

To cite Devauchelle V, Saraux A. Ann Rheum Dis 2016;75:e48.

Received 11 May 2016

Accepted 14 May 2016

Published Online First 6 June 2016

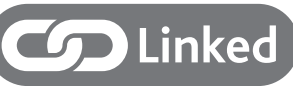

http://dx.doi.org/10.1136/annrheumdis-2016-209596

Ann Rheum Dis 2016;75:e48. doi:10.1136/annrheumdis-2016-209607

REFERENCES

1 Moiseev $S$, Novikov $P$, Fomin V. Tocilizumab for polymyalgia rheumatica: a first or second line? Ann Rheum Dis 2016;75:e47.

2 Devauchelle-Pensec V, Berthelot JM, Cornec D, et al. Efficacy of first-line tocilizumab therapy in early polymyalgia rheumatica: a prospective longitudinal study. Ann Rheum Dis 2016;75:1506-10.

3 Palard-Novello X, Querellou S, Gouillou M, et al. Value of (18)F-FDG PET/CT for therapeutic assessment of patients with polymyalgia rheumatica receiving tocilizumab as first-line treatment. Eur J Nucl Med Mol Imaging 2016;43:773-9.

4 Dejaco C, Singh YP, Perel P, et al. 2015 Recommendations for the management of polymyalgia rheumatica: a European League Against Rheumatism/American College of Rheumatology collaborative initiative. Ann Rheum Dis 2015;74:1799-807.

5 Dejaco C, Singh YP, Perel P, et al. 2015 Recommendations for the Management of Polymyalgia Rheumatica: a European League Against Rheumatism/American College of Rheumatology Collaborative Initiative. Ann Rheum Dis 2015;67:2569-80

6 Lally L, Forbess L, Hatzis C, et al. A prospective open label phase lla trial of tocilizumab in the treatment of polymyalgia rheumatica. Arthritis Rheumatol 2016. doi:10.1002/art.39740. [Epub ahead of print 9 May 2016].

7 Hunter CA, Jones SA. IL-6 as a keystone cytokine in health and disease. Nat Immunol 2015;16:448-57. 